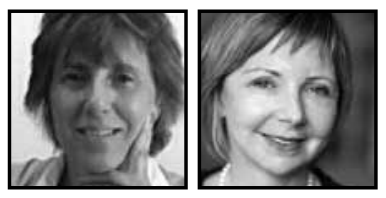

\title{
E-Learning Pedagogy: Addressing Struggling Learners in Regular K-12 Classrooms as an Intransigent Design Problem
}

\author{
Susan Imholz and Ricki Goldman, New York University
}

\begin{abstract}
As online education providers gain a foothold in the US public education system nationwide as supplemental and primary providers of curriculum materials, they are replicating some of the same pedagogical mistakes that brick-and-mortar schools have created in the curriculum development process-by not accommodating the struggling learner. Our paper and discussion concerns K-12 online content providers and their curriculum development processes.
\end{abstract}

\section{The Problem}

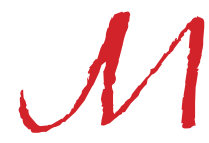

any e-learning virtual education providers have mastered the art of creating electronic books, however they may not be employing pedagogical practices that are easily accessible to challenged learners, who are technologically unsophisticated. In many ways they are repeating the same structural weaknesses of traditional schools by designing materials that address the motivated, talented learner at the expense of students who are on either side of "the bell curve," so to speak. More specifically, online education providers are producing curriculum whose goals are implicit, but unstated in procedural descriptions of their use in the context of school classrooms, or informal alternative education settings where students are accessing e-learning platforms. Furthermore, these platforms are biased toward the culturally sophisticated student who has had the benefits of supplementary socioeconomic support in the form of $24 / 7$ access to computer 
resources, tutoring, and enriched electronic learning environments; the same group who has been the most well served in traditional public schools in the past. While online e-learning has the ability to personalize the learning process for students, most are not taking advantage of these design capabilities, or recent education research which addresses struggling K-12 students (Hoover, 2011; Israel, Maynard, \& Williamson, 2013; Joseph, 2010; Lightbrown, 2010; Misquitta, 2011; Slama, 2012). Taking into consideration the perspective of the learner, and students' particular needs, is the new creative challenge for instructional designers. This is both a design issue and a pedagogical issue, which is how we will address the problem going forward.

The problem, as we have stated it, is tangential to an ongoing line of inquiry as to why cognitively oriented technology innovations have not been adopted and become more widespread in K-12 schools. Fishman, Marx, Blumenfeld, Krajcik, and Soloway (2004) explored this question at length and came to the conclusion that

...a primary reason is that research to date has not focused on issues of how such innovations function at the level of school systems. This results, in part, from the fact that much design-based research focuses on a designed product or resultant theory and not the system variables that impact the scaling potential of the work beyond the sites where the research was carried out. (p.69)

Today — over eight years later-the marketplace has provided a means for entrepreneurs and online education companies to access public funds for delivery of distance learning platforms in public schools, but has largely circumvented issues of quality and efficacy in regard to pedagogy. One way of looking at this situation is that we now have two parallel K-12 design systems (traditional schools and virtual online education providers) that have not assimilated the most innovative and powerful uses of technology for learning.

In this paper we employ a historical lens proposed by Le Masson, Hatchuel, and Weil (2011a), experts in strategic management and innovation, to broaden the discussion of innovation integration to a systems level analysis as Fishman suggested. This approach assists us in thinking about why online learning platforms have not been able to incorporate new knowledge, strategies, and models shown to provide additional scaffolding to struggling learners. The historical perspective that Le Masson and colleagues have crafted and that we are sharing, integrates psychology, cognitive science, and management of creativity with engineering science in the formation of design science. A full description of their work can be found in their 
book, "Strategic Management of Innovation and Design" (2011b), which addresses the types of project management structures and processes that support truly innovative design, versus the design and manufacture of objects that are well established in the marketplace.

\section{The Historical Perspective}

Le Masson et al. (2011a) analyzed the relationship between creativity issues and design methods with interesting results, shedding light on why current developers of online curriculum are misfiring as we will show further on. In preliminary work on the topic of creativity and design,

...Hatchuel (2011) noted that recent design theories form a consistent body of knowledge that tends to increase the creativity of design. This result seems to confirm our belief that there are historical dynamics linking creativity issues and the development of new models of design reasoning. (2011a, p. 218)

This premise prompted the research question explored by Le Masson et al.an investigation into the assumption

...that new models of design reasoning emerged to address new creativity issues; that the models that led to wide-spread methods [of product development] also helped to better address these creativity issues; and that the models and related methods were finally criticized [and replaced] for not addressing new, emerging creativity issues. (p. 218)

So to summarize, Le Masson and colleagues propose that design theories and methods evolve to meet the creative challenges of historical circumstances. As this relates to established design efficiencies for digital curriculum development, the challenge to the status quo involves a dialogue between new learning science, unique affordances of new media, and the limits of traditional forms of design activities. For purposes of our discussion, we are going to generalize from experience in the field and hypothesize that a majority of online education providers are presently employing a four-step method of curriculum design: 
1. Using K-12 US state and Common Core subject matter standards as guidance for the development of courses, companies employ subject matter experts to write curriculum content and structure lessons in text format, inserting multiple choice exams for pre and post comprehension.

2. This material is transferred into digital media, which involves passing content to technical staff who define the look and organization of the learning platform web pages, add graphics, animation, and perhaps audio narration of text, to enhance textual material.

3. A quality review of the completed lessons is done for accuracy, consistency, alignment with standards, and proofreading.

4. All of the previous phases of activity are taking place in multiple locations, some or all of which may constitute a virtual project management enterprise in design and delivery.

To make accommodations to students of differing levels of ability or knowledge, spaced repetition (Bjork, 1994, 2011; Bjork \& Linn, 2006) is a favored pedagogical approach used in online learning platforms to capture struggling learners who are in need of extra reinforcement when presented with new ideas and concepts. However, reading the material again more closely is not a strategy you can expect to work if there is a basic comprehension issue. What is needed instead are opportunities for students to revisit the same material in a somewhat different way so that comprehension can occur. If digital technology can offer many scaffolding strategies for doing this (Wu \& Looi, 2012; Shapiro, 2008; Stewart, Maclntyre, Galea, \& Steel, 2007; Deakin-Crick, 2007; Holton \& Clarke, 2006; Graesser, McNamara, \& VanLehn, 2005), why is it they are rarely used in K-12 e-learning pedagogy?

Our view is that online platform providers need to embrace advances from the well-established field of learning science which has called for designers to become more creative and also more focused on the inclusion of all students. Is this lack of progress primarily a knowledge problem? A barrier to advancement caused by financial constraints? Or, is it a glitch in the production process? Let's turn to the work of Le Masson and colleagues for further direction. Their insights and analysis of how design theories incorporate and resolve creative challenges provide a framework and language for deconstructing the problem. What follows is a much-abbreviated synopsis of their work. Pascal Le Masson is professor and chair of the Design, Innovation, and Management in Engineering Design (MINES) program at Paris Tech. His colleagues, Armand Hatchuel and Benoit Weil, are on the faculty in the same program. 


\section{The Three Tensions Between Creativity Issues and Design}

Le Masson, Hatchuel, and Weil investigated the interplay between established production and design practices and the creative forces impinging upon them to bring change. Their study gives us a fuller understanding of how businesses and institutions get stuck in the wrong production and problem-solving models. The rubric used in analysis is composed of three tensions, which are defined as the central drivers of change:

(1) How to apply new knowledge:

- How is knowledge managed?

- What is the absorptive capacity of human resources to digest new information?

- What are the knowledge "fixations" of the organization, or its core rigidities?

(2) Defining the design process as divergent or convergent:

- Creativity tends toward divergence, and divergent thinking

- Production processes typically involve initial divergence, followed by convergence

(3) Organizational leadership characteristics (linear or circular):

- Established product management styles are strongly linear (one-way directives), and therefore poorly structured to adapt to creative teams (circular process) vs. dominantly circular management style where focus and productivity are lost

- An overly linear product management style may stifle absorptive capacities of staff and lose opportunities to apply new knowledge; circular management may not converge on solutions in a timely way

As subjects for study, the authors chose three different design theories that emerged over time, each considered to be a milestone in the evolution of the field of design science. The time line spans from the mid 1800s to the mid 1900s. The three theories, ratio theory, systems design theory, and Bauhaus design theory, were each examined in relation to different product development processes and outcomes: (1) ratio theory and the development of algorithmic thinking as it applied to construction of water wheels; (2) systems design and the creation of formalized product management organization and research and development departments (R\&D) as applied to automobile companies, pharmaceutical companies, and electronic manufacturing; 
(3) Bauhaus design and the cultivation of creativity as subject matter in industrial design, formalizing activities that institutionalized "a form of mutually addressed collective creativity" (2011a, p. 231) in the product development enterprise.

In quick summation, Masson and colleagues noted that each successive design theory incorporated a greater number of creativity issues and variables, and these issues were drivers of innovation. Additionally, they perceived "fixation effects" or perseverative behaviors and practices which were creative impediments. In turn, these fixations spawned new design theories and models of thought to overcome them. Fixation effects can be mechanical or material in nature, related to managing knowledge, or organizational processes according to the authors. A closer look at all of the case studies will allow us to return to our subject of current online curriculum production methods with a heightened sense of awareness about the creative and administrative forces impinging upon and "fixing" the status quo.

\section{The Method of Ratios}

In the first case, the method of ratios was studied. As design theory, the ratio method emerged as an innovative solution to a fixation on the replication of existing objects (water wheels) with little variation. The originator of the method was an accomplished engineer and instructor in Germany's Technishe Hochschule in Karlsruhe named Redtenbacher. Professor Redtenbacher devised a series of diagrams and a decision-point script that technical builders of water wheels would review prior to meeting with a potential client and surveying the features of the landscape (Redtenbacher, 1858). The script addressed four key variables: the client's budget, the choice of a metal or wooden wheel, the height and water fall flow, and useable flow. These determining features, in turn, specified which of Redtenbacher's diagrams to employ for further guidance. Redtenbacher's diagrams provided stepby-step directions on construction of all the parts needed to complete the customized water wheel. These plans were dimensionless, but showed the ratios between all the parts. According to the rubric developed by Le Masson and colleagues (2011a), the three tensions that shaped the ratio method were:

\section{Knowledge}

- The ratio method provided models of existing objects and guidance as to how to use and extend expert knowledge and adapt it to many different contexts.

\section{Convergence vs. Divergence}

- The ratio method ensured convergence towards one acceptable 
solution, but it also prevented the builder from converging too quickly on a design.

- Redtenbacher's script identified precisely the moment in the design process when it was possible and fruitful to diverge the construction process and the type of investigation that was relevant.

\section{Product Management \& Organization}

- The ratio method defines specific forms of dividing work; the script distinguishes between two roles in the design process-the expert rule maker (Redtenbacher) who designs rules, and the builder who is the rule user.

- The rule maker exerts leadership by extending his knowledge and defining areas of freedom to be delegated to the rule-user, and the builder exercises creativity in the execution of the plan.

\section{Systems Design Theory}

In the second case, systems design (SD) was studied. Systems design emerged in the 1920s and 1930s as "a method that reopens spaces for creativity, pushing designers NOT to re-use existing knowledge but to explore new knowledge...in a rigorous efficient way" (2011a, p. 225). As assembly line production facilities sprang into existence in the 20th century for automobiles, pharmaceuticals, and electronic devices, product management and development procedures began to rigidify. This gave rise to a form of design fixation in which "designers tended to re-use outdated and obsolete design rules, or fix upon existing rules and machine elements" (p. 224). Systems design reasoning was devised to front run the product development manufacturing process by introducing robust knowledge exploration, knowledge acquisition, and absorption phases prior to the finalization of specs for production purposes. Design exercises were incorporated into the workplace for teams of designers which included: a) cataloging all possible solutions to a design problem prior to penning prototypes, b) a design materials exploration phase, c) an added phase for descriptions of functional linkages between sub elements where testing and error analysis was conducted in recursive fashion, d) lastly, descriptive prototypes were created which became the basis of final product making. According to Le Masson and colleagues, the three tensions that shaped systems design were:

\section{Knowledge}

- $\quad$ SD aims to fight the fixation caused by existing design rules-it recommends when rules should be used and devised supports for the creation of new knowledge for expansion at the right time. 


\section{Convergence vs. Divergence}

- SD organizes convergence by predefining the order in which known objects should be described and defined. The hierarchy of steps maintains divergence in the process.

\section{Production Management \& Organization}

- SD enables an increasing level of complexity in the engineering of projects. It also facilitated the systematic design of subunits that ensured their integration by recursive testing and analysis loops prior to finalization of a prototype.

\section{Bauhaus Design}

In the third and last case study, the authors looked at Bauhaus design methods. Bauhaus, as a set of design principles, was derived from the curriculum of Walter Gropius and his school for artists and designers in Germany in 1919. Le Masson and colleagues characterized Gropius' mission this way: "[the school] aimed to serve the modern development of housing from the simplest appliance to the whole dwelling" (p. 227). Paul Klee, Wassily Kandinsky, and Joseph Itten were all faculty members who were instrumental in developing program courses. What distinguishes the Bauhaus from other design theories and methods of its time is its emphasis on the cultivation of imagination and creativity as skills and sensibilities that can be strengthened as opposed to inherent gifts. Class exercises challenged students' perceptions of the world, their biases, and instinctual associations between form, function and aesthetics. Le Masson and colleagues describe Itten's vision of the process as "developing a theory of contrasts [which] aim to open new creative worlds to students not only in the sense of providing new means of expression but also of improving perceptions" (p. 228). The fixation that the Bauhaus method resolved is one of fixed associations and attributes of things, which artists and designers absorb unconsciously. These associations include: form with color, form with specific materials, textures, in short "clichéd" design practices that become an obstacle to original ideation. The Bauhaus program was highly structured and systematic in its approach, cultivating teams of designers in a group process that strengthened their ability to critique and support one another. Students were first introduced to sensory exercises: they studied old masters to learn rules of composition; then drew from memory and feeling instead of training their eye for faithful reproduction of objects; they engaged in tactical exercises to sharpen observations and sense of touch. After this series of experiences, students were afforded more self-directed research and finally art production. The end product was, by design, art/object making inspired from the inside-out-creativity that was not based on imitation but personal interpretation, infusing products 
with artistic uniqueness. Ultimately, the Bauhaus approach to design impacted many different products including furniture, building design, typography, and consumer goods. According to Le Masson and colleagues, the three tensions that shaped Bauhaus design were:

\section{Knowledge}

- The Bauhaus devised a method for designing new textures and household goods based on overcoming the clichés and limitations of fixed associations to promote creative expansion.

\section{Convergence vs. Divergence}

- Bauhaus methods encouraged a multi-layered approach to exploration of materials that converges with the final product.

\section{Production Management \& Organization}

- Bauhaus method focuses on the development of cohorts of students who learned to compare and contrast their work, to develop their creative powers.

- Bauhaus methods combined art and technique in a novel way, by cultivating imagination first before product design, and was characterized by strong leadership.

\section{Historical Analysis and Its Application to Online Curriculum Design}

The historical approach is useful for many reasons. It allows us to: learn from the past, look more closely at the intricacies and complexities of the design process as an evolving problem-solving activity, gives us a context for examining our current design problem as a whole gestalt, and provides us with a better understanding of why we are where we are today. The key findings of Le Masson and colleagues relate to dialectical tensions spurring change, and were identified as; (a) opportunities for new knowledge integration, (b) when convergence vs. divergence is needed in regard to increasing opportunities for creative influence, and (c) how the product development process is managed.

Using this rubric to evaluate the current status of online K-12 education curriculum and the four-step design process, we define the systemic creative challenges to higher production values as: 
$>$ A solution to enable designers to integrate and use new knowledge about a variety of learning styles at the right moment in the curriculum development process

How should new knowledge be shared and distributed throughout the organization? Decisions about new knowledge required in course production follow from making a commitment to a particular population of students, getting to know the needs of those students very well, which in turn informs choice of pedagogical strategies for curriculum development.

$>$ A solution to prevent designers from continuing to reuse obsolete design rules

The current rules for curriculum design are replicating content in such a way as to represent a previous media-books - and thereby replicate a "one-size-fits-all" approach to course development. This fixation is rooted in institutional and bureaucratic structures (publishing companies and school systems) which are over a century old with deeply ingrained organizational methods. The four-step process lacks structured divergent exploratory phases on two important dimensions in the production process: learner modeling (what are online companies learning about their students that can be fed back into the curriculum design process), and exploration of technology's unique characteristics for fostering collaboration and engaging learners.

$>$ A solution to enhance and refresh representations of students which change the definition of student engagement, creating a richer portrait of the learner

The core knowledge deficit and creative challenge in regard to upgrading the curriculum development process, as we see it, is an in-depth understanding of the learner. This requires building more comprehensive design descriptions of student behaviors. One way to begin this process with design teams is by creating dialogue and asking questions. For example, how would instructional designers incorporate additional student feedback in the learning platform that included:

- informal knowledge students bring to their studies

- students' degree of understanding of the material presented through a choreographed line of questioning

- emotional tone and attitude the student brings to the activity

- students' ability to engage with the technology and learning platform that is being presented 


\section{Organizational Management}

In the K-12 world, one course will never be designed to work for all potential learners; the diversity of student needs in public school systems is simply too broad. This is the sticky wicket that public K-12 education has as its mandate, nevertheless. In regard to management style, Le Masson and colleagues might suggest what is needed to succeed in the marketplace is strong executive leadership with subject matter expertise in learning science, and a management team that can set priorities flexibly and define a student and product focus within an organization.

In practice, entrepreneurial companies tend to have a linear style of managing the product development enterprise, and more often than not, have no research and development departments to advise them. The marketplace drives course development-what potential clients want and need is the primary impetus for new course creation. Timing is also an important factor, which means that there is no room for reflection upon the template for course development if you need to be first to market. These are the stark realities and financial constraints shaping the design of curriculum materials for entrepreneurs. On the other hand, many of the larger corporate and institutional players in the marketplace with R\&D departments and bigger budgets have not overcome bureaucratic structures and rules locking them into the four-step design model, and consequently do not innovate.

\section{Good Design for Struggling Learners}

The Bauhaus design method is a superb model for good online curriculum for struggling learners. Here, we are bypassing Le Masson and colleagues' contextual presentation of the Bauhaus method as a management production process, and discussing the method as it applies to the design of education software. The notion that creative exploration and skill building need to precede problem solving and concept evaluations for K-12 students has been a feature of many project-based software programs for a long time, beginning with Seymour Papert's Logo (Papert, 1980; CTG at Vanderbilt, 1992; Schank \& Cleary, 1995; Barron \& Darling-Hammond, 2008). This method of structuring curriculum allows for formative assessments of student skills and the front-loading of remedial instruction, sparing many struggling students from the odor of defeat and failure that testing imposes upon them as a screening device versus an evaluation of understanding. The Bauhaus approach can also provide struggling learners with an opportunity to review and absorb academic material many different ways so that comprehension can occur. Our present-day exemplar of design of this caliber is the work of the Concord Consortium. ${ }^{1}$ Their open source 
web-based software materials are focused on science and mathematics, are built by experts, and are free to students and teachers. Now the proviso: we have to acknowledge that the expense of creating Concord Consortium programs and the costs associated with supporting its software platform are considerable, and may be beyond the reach of many entrepreneurs entering the marketplace of online education. The good news is that it's already available.

As Le Masson and colleagues' analysis of the Ratio Method demonstrates, the level of support for transferring expert knowledge to a broader audience is central to its being scalable and this seems to be another issue at hand. If we look at our stated problem a little differently by taking into account the availability of welldesigned software that is free to be used by anyone or any organization, then a solution to improving online curriculum quality for struggling learners is readily at hand. Online education companies might consider creating a new management function in the form of a modern master builder who is a pedagogical expert, who can discriminately supplement traditional base-line curriculum with exploratory, skill-building games, and software projects that are free in the media membrane. This is cost efficient, and an immediately actionable means of upgrading product offerings with the added benefit of spurring internal comparative analysis.

\section{The Role of the Regional Accreditation Boards in Improving Online Education Products}

There are external pressures on online education providers, large and small, to take stock of their design methods and instill more circular and recursive production processes. The most influential are US regional and accreditation bodies. Many online education companies are choosing to become accredited with national review boards that have opened candidacy to virtual education providers. They include: the North Central Association Commission on Accreditation and School Improvement (NCA CASI), Southern Association of Colleges and Schools Council on Accreditation and School Improvement (SACS CASI), and Northwest Accreditation Commission (NWAC), Western Association of Schools and Colleges (WASC), and New England Association of Schools and Colleges (NEASC). E-learning companies are signing on because of financial incentives which accrue upon being successfully accredited, along with the requirement that they do so by US state level Departments of Education in order to obtain contracts to provide supplemental and full online course programs to students. At this date, there are 46 states that provide supplemental online education to K-12 public schools, the majority of which are high school courses, and 28 states that provide full-time online curriculum to a much smaller number of 
schools serving mainly high school students. Once an online provider decides that it will embark on the accreditation process, it performs a "self-study" analysis. This review is guided by the accrediting agency and includes a thorough examination of the organization's programs and courses, teaching and tutoring faculty, facilities and resources. Preparation for a first official review may take a full year, depending upon the readiness level reported by preliminary survey assessments and the types of remediation structures an online provider chooses to put in place before being evaluated.

The type of data collection processes that online education companies are asked to adopt in the accreditation review includes closing the loop on perceptions of curriculum quality among all stakeholders. Surveys weigh student, parent, and teacher feedback equally with that of the organization's administration. Above all, it is the accrediting bodies' mandate to implement a variety of benchmarks that chart a course of continuous qualitative improvements across all aspects of the education provider's company that has impacted the e-learning marketplace significantly (including: administration, teacher professional development, curriculum quality). Benchmarks require data points that don't currently exist for many online providers, which prompt considerable internal re-organization. The collective wisdom of accrediting agencies is that they are imposing circular evaluation processes, devoid of content or explicit management directives, to create organizational improvements. Benchmark indicators of success are self-defined by accreditation candidates, encouraging integration of "continuous improvement" goals and objectives with company/organization core mission, values, and strategic plans. The accreditation process also requires the full participation of company staff in the evaluation review, which has changed the character of organizational development and caliber of professional development activities.

Bringing the discussion back to changing the prevalent digital curriculum design culture, we can see that signing onto the accreditation review process will disrupt the four-step method and accelerate the expansion of new phases of design and creativity challenges by: (a) encouraging the integration of feedback from students, parents, and other stakeholders with curriculum improvements, providing a richer portrait of students and student needs, (b) encouraging the use of data and feedback from students, parents, and other stakeholders in developing professional development activities across the organization which are specifically tied to perceived deficits. 


\section{Conclusion}

We began with the observation that virtual education and e-learning platforms, by and large, seem to be replicating 20th century methods of education in digital formats. Le Masson, Hatchuel, and Weil provide us with a deeper understanding of what this means, and how the procedural and perceptual shifts in our use of technology bring new creativity issues into focus. Moreover, the authors' historical analysis reveals the complexity of design evolution, and the interplay of factors involved in repetitive production models that have outlived their usefulness. We used this work to help clarify the creative challenges and tensions "fixing" uses of technology in curriculum development for online education. The obstacles to change in e-learning design are a confluence of factors and tensions that are characteristic of our historical moment.

What would also be helpful is a kind of "truth-in-labeling" criteria in the pedagogical approach used by e-learning courses which is described and categorized in such a way that it becomes visible to the clients (school systems, teachers, parents, and administrators) whether a course is actually designed to address the target population it claims to serve. We suggest that online education providers: (a) examine their model of the learner and the learner's experience for depth and complexity in regard to their pedagogical goals; (b) raise questions with their design teams as to whether they are incorporating a sufficient number of design phases and variables to accommodate multiple learning styles, and to address the populations that they purport to serve; (c) urge management to incorporate these issues and questions into plans for continuous improvement, and organizational evaluation of effectiveness; (d) integrate the use of well-designed, high-quality project-based software materials that are freely available online. We also acknowledged the important role US regional accreditation bodies are playing in accelerating change in design methods used by online education companies.

\section{Note}

1. Please see Concord.org 


\section{References}

Barron, B., \& Darling-Hammond, L. (2008). Teaching for meaningful learning: A review of research on inquiry-based and cooperative learning in Powerful learning: What we know about teaching for understanding. San Francisco, Jossey-Bass.

Bjork, R. (2011). On the symbiosis of learning, remembering, and forgetting. In A. S. Benjamin (Ed.), Successful remembering and successful forgetting: a Festschrift in honor of Robert A. Bjork (pp. 1-22). London: Psychology Press.

Bjork, R. A. (1994). Memory and metamemory considerations in the training of human beings. In J. Metcalfe and A. Shimamura (Eds.), Metacognition: Knowing about knowing (pp. 185-205). Cambridge, MA: MIT Press.

Bjork, R. A., \& Linn, M. C. (2006). The science of learning and the learning of science: Introducing desirable difficulties. American Psychological Society Observer, 19, 29, 39.

Cognition and Technology Group (CTG) at Vanderbilt (1992). The Jasper series as an example of anchored instruction: Theory, program description and assessment data. Educational Psychologist, 27(3), 291-315.

Deakin-Crick, R. (2007). Learning how to learn: the dynamic assessment of learning power. The Curriculum Journal, 18(2), 135-153.

Fishman, B., Marx, R., Blumenfeld, P., Krajcik, J., \& Soloway, E. (2004). Creating a framework for research on systematic technology innovations. The Journal of the Learning Sciences, 13(1), 43-76.

Graesser, A., McNamara, D., \& VanLehn, K. (2005). Scaffolding deep comprehension strategies through Point\&Query, AutoTutor, and iSTART. Educational Psychologist, 40(4), 225-234.

Holton, D., \& Clarke, D. (2006). Scaffolding and metacognition. International Journal of Mathematical Education in Science and Technology, 37(2), 127-143.
Hoover, J. (2011). Making instructional adjustments to RTI models: Essentials for practitioners. Intervention in School \& Clinic, $47(2), 82-90$.

Israel, M., Maynard, K., \& Williamson, P. (2013). Promoting literacy-embedded, authentic STEM instruction for students with disabilities and other struggling learners. Teaching Exceptional Children, 45(4), $18-25$.

Joseph, N. (2010). Meta-cognition needed: Teaching middle and high school students to develop strategic learning skills. Preventing School Failure, 54(2), 99-103.

Le Masson, P., Hatchuel, A., \& Weil, B. (2011a). The interplay between creativity issues and design theories: A new perspective for design management. Creativity and Innovation Management, 20(4), 217-238.

Le Masson, P., Weil, B., \& Hatchuel, A., (2011b). Strategic management of innovation and design. New York: Cambridge University Press.

Lightbrown, P. (2010). Struggling Learners and Language Immersion Education: Research-Based, Practitioner-Informed Responses to Educator's Top Questions. Center for Advanced Research on Language Acquisition, Minneapolis: University of Minnesota.

Misquitta, R. (2011). A review of the literature: Fraction instruction for struggling learners in mathematics. Learning Disabilities Research \& Practice, 26(2), 109-119.

Papert, S. (1980). Mind storms: Children, computers, and powerful ideas. New York: Basic Books.

Redtenbacher, F. (1858). Theorie und Bau der Wasser Räder, 2nd ed. Bassermann: Mannheim.

Schank, R., \& Cleary, T. (1995). Engines for education. Hillsdale, NJ: Lawrence Erlbaum Press.

Shapiro, A. (2008). Hypermedia design as learner scaffolding. Educational Technology Research \& Development, 56(1), 29-44 . DOI 10.1007/s11423-007-9063-4 
Slama, R. (2012). A longitudinal analysis of academic English proficiency outcomes for adolescent English language learners in the United States. Journal of Educational Psychology, 104(2), 265-285.

Stewart, T., Maclntyre, W., Galea, V., \& Steel, C. (2007). Enhancing problem-based learning designs with a single e-learning scaffolding tool: Two case studies using Challenge FRAP. Interactive Learning Environments, 15(1), 77-91.
Wu, L., \& Looi, C. (2012). Agent prompts: Scaffolding for productive reflection in an intelligent learning environment. Educational Technology \& Society, 15(1), 339-353.

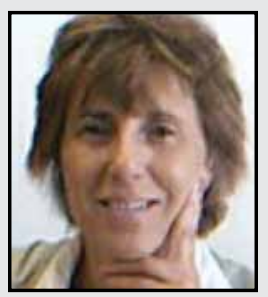

Susan Imholz is an educator and learning technology consultant to schools and non-profit organizations, and her work has been supported by the National Science Foundation, MacArthur Foundation, and the Bill \& Melinda Gates Foundation. As a program designer, she employs technology as a creative and expressive medium enriching educational objectives at all grade levels. Dr. Imholz is currently working on a book entitled, "Psychology's New Design Science: Theory \& Innovation in the Use of Art and Media Technology."

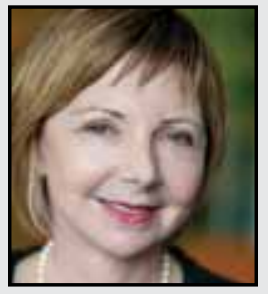

Ricki Goldman is Professor of the Digital Media Design for Learning in the Educational Communication \& Technology Program at NYU. She is a founding faculty member of NYU's multi-school facility, MAGNET (Media and Games Network) opening in September of 2013 at NYU Poly. Goldman is a learning and media theorist and an inventor of tools for ethnographic video data analysis. One of her books, Points of Viewing Children's Thinking: A Digital Ethnographer's Journey (LEA, 1998), was accompanied by the first interactive website with online video cases and tools for commentary.

\section{LINK TO:}

http://steinhardt.nyu.edu/faculty_bios/view/Ricki_Goldman

http://www.pointsofviewing.com 